\title{
A Feature Percolation Convention of Affixation Processes in Urhobo
}

\author{
Bestman Esegbuyiota Odeh* \\ (University of Nigeria, Nigeria)
}

\begin{abstract}
This paper seeks to examine headedness in affixation processes in Urhobo using a feature percolation approach. Affixation is a rich source of word formation process in the Urhobo language. The specific objectives are to identify affixation processes in Urhobo, investigate how they are used to derive words and determine headedness in the Urhobo language using a feature percolation theory as a framework. This paper reveals three affixation processes in Urhobo, which are prefixes, circumfixes and suffixes. Affixation is a derivational aspect of morphology and it brings about change in the grammatical class of the word or rather, provides additional semantic information to a word. The paper discovers that new words are derived in the language by attaching an affix either at the beginning (prefix), or to the end (suffix) of a word. This process is very productive in the language. The paper reveals that the head of a word using prefix is left-right branching while for suffixes, it is right-left branching. The prefix and suffix attached to a root to form the circumfix project to be the head of a word. The study observes circumfixes to have two heads. Feature percolation theory is also used to determine the head of a word in Urhobo. The paper concludes by recommending further researches on the use of theories especially morphological theories in analysing morphological processes in Urhobo.
\end{abstract}

Keywords: affixation, Urhobo, head, percolation, morphology, syntax

\section{Introduction}

Language is a means of communication, which brings life to a speech community. Humans use language to communicate with one another. Language is as important as any living creature. Animals also communicate with the use of language. Urhobo language is a language spoken in the southern part of Nigeria and majorly spoken in Delta region. The people of Delta are known for farming, fishing, etc. Urhobo belongs to the Edoid language of the Niger-congo language family. The Edoid languages fall into four primary subgroups: Delta Edoid, South Western Edoid, North Central Edoid and Western Edoid. South Western Edoid is sub-divided into five regional groups: Erohwa (Eruwa), Isoko, Urhobo, Okpe and

\footnotetext{
* Bestman Esegbuyiota Odeh: Assistant Lecturer, Department of Linguistics, Igbo and Other Nigerian Languages, University of Nigeria, Nsukka. E-Mail: bestman.odeh@unn.edu.ng.
} 
Uvwie (Elugbe, 1989). The traditions among the Urhobos are replete with assertions of original dwellers and owners of their territory. These autonomous people were believed to be Urhobo, with no known history of migration from anywhere else. These traditions are without documentary or archaeological evidence. Linguistic evidence provides a strong principle for integrating and validating other traditions of Urhobo origin.

Every language has its own way of creating words of which Urhobo language is not exempted. In all languages, a simple word may be expanded and changed in meaning by the attachment or insertion of one or more units of meaning called morphemes. Urhobo involves in word formation processes including: affixation, borrowing, compounding, reduplication, etc. For this paper, only affixation processes will be discussed. Affixation is a rich source of word formation process in the Urhobo language and a derivational aspect of morphology in this language. It is the process of adding a morpheme in order to modify the meaning of a word. Affixation processes are connected with productivity in the Urhobo language. Ndimele (1999:22) defines affixation as 'a morphological process of attaching an affix to the root or base of a word'. Agbedo (2000:89) sees affixation as the 'process that involves the addition of a phoneme or group of phonemes to a root or stem to modify, extend or change the meaning and/or function of the word'. Affixations are derivational morphemes used to derive lexemes from existing words (Babarinde, 2009). Furthermore, from the phonological perspective, Agbedo (2015:187) defines affixation as 'a speech sound or a group of speech sounds, which is added to a word and changes the meaning or function of the word'.

The paper seeks to examine headedness in affixation processes in Urhobo using a feature percolation approach for analysis of data. The specific objectives are to identify affixation processes in Urhobo and investigate how words are derived and to determine headedness in Urhobo using a feature percolation theory as a theoretical framework for the analysis of data. This paper covers two areas which include: Abraka and Agbarho. The significance of the paper is to provide materials for the teaching and learning of Urhobo and to also expand the vocabulary of the Urhobo language. There are works on affixation processes in Urhobo but much attention has not been given to the use of a theory for the analysis especially the morphological theories. To the best of the researcher's knowledge, no work in Urhobo adopts a feature percolation theory for the analysis of data. This paper tends to fill the limited gap by using a feature percolation theory to examine headedness in affixation processes in the Urhobo language.

The feature percolation theory will be adopted as a theoretical framework for this analysis. In gathering data for analysis, the researcher used introspection and also interviewed native speakers of the language for the validity of literature. The study covers the Urhobo spoken majorly in Abraka and Agbarho areas of Delta state.The study adopts 
the descriptive survey research design.

\section{Conceptual and empirical review of related literature}

According to Ejele (2005), an affix is a morpheme that only occurs when attached to some other morphemes (stem, root, base). Affixes never occur on their own, and they are bound materials attached to another entity to derive its meaning. Affixes are richly used in many languages such as Igbo, Hausa, Urhobo, Yoruba, Ibibio, etc. to derive new words. Owolabi (1995) in Amajoyi (2017) classifies class 1 prefixes as those prefixes attached to roots that are verbs or verb phrases. The claim that class 1 prefixes are heads by virtue of the fact that they assign the category $\mathrm{N}$ to the entire complex noun of which they are part, implies that prefixes themselves must also bear the category label N. Examples as stated by Owolabi (1995) in Yoruba include:
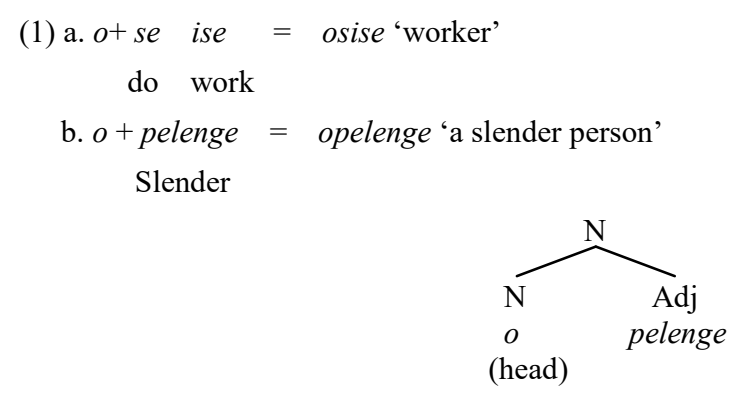

Figure 1. Class 1 prefix

From the illustration above, the Yoruba language clearly shows that the head of the complex words is located on the left-hand side (Amajoyi, 2017). Owolabi (1995) proves that prefixes are heads in the Yoruba language as seen in the examples (1a-b) above (cf. Mbah, 1999; Harris, 1951; Selkirk, 1982; Zwicky, 1985; etc.).

Williams (1981) points out, given the Right-hand Head Rule (RHR) and percolation, the compound structures below may be the realisation of the plurals of the compound nounsapron string and Canada goose and of the past tense forms of the verb compounds outlive and underfeed.

(2) a.

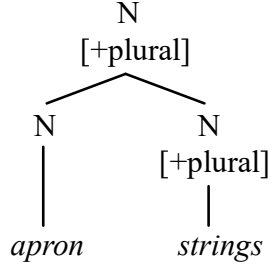

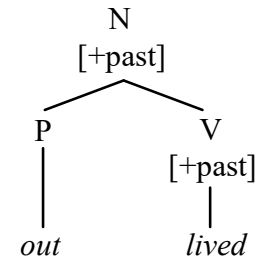


b.

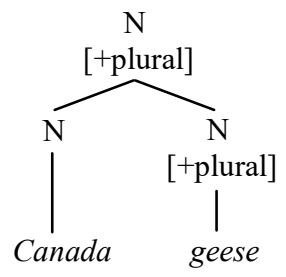

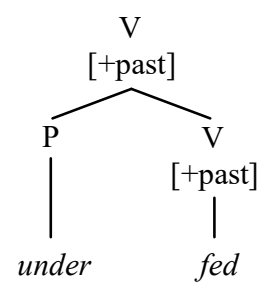

Figure 2. Right-hand head rule (realisation of plural compound nouns)(Amajoyi, 2017:13)

The general linguistic notion is that roots alone are heads. In contrary to the general notion, Amajoyi (2017) notes that heads are essentially in the same way it is used in syntax where the head of a construction is what determines the syntactic category. In the same vein, Williams (1981) opines that whatever determines the grammatical class or provides additional semantic information to the word is what is referred to as the head. This work aligns its thought to that of Williams. Selkirk (1982) opines that the head of a constituent plays a crucial role in the description of the distribution of the diacritic feature related to both inflectional and derivational morphology. Williams (1981) proposes that affixes like other morphemes may be assigned syntactic category features. Selkirk interprets this to mean that the rewriting system for affixation generates structures in which one of the daughters, either the affix or its sisters, bears the same syntactic category of an affix's mother which is not the same as the category of its sisters, then, it must be that the affix is the head.

Affixation is a word-building or word formation process that involves the addition of a phoneme or group of phonemes to a root or stem to modify, extend or change the meaning and/or function of the word. Affixes are class changing and meaning maintaining. Affixes are classified in terms of position and function. Positional affixes involve prefix, suffix, infix, interfix, circumfix, suprafix, etc., while functional affixes are inflections and derivations. Functional affixes change the class of the word but preserve its meaning. Agbedo (2000) notes that derivational affixes involve the change from one grammatical category to another or the change of sub-class. The data in English below justify Agbedo's idea.

$\begin{array}{cl}\text { (3) a. Noun } & \text { Verb } \\ \text { character } & \text { characterize } \\ \text { danger } & \text { dangerous } \\ \text { b. Verb } & \text { Noun } \\ \text { object } & \text { objection } \\ \text { annul } & \text { annulment } \\ \text { c. Noun } & \text { Adjective } \\ \text { milk } & \text { milky }\end{array}$




$$
\text { girl girlish }
$$

In the case of inflectional affixes, they introduce change to reflect tense, person, aspect, number, possession, comparatives and superlatives. Positional affixes such as prefixes are attached to the beginning part of a word to bring about change in class or meaning. (Agbedo, 2000).

Ejele (2005) notes that prefixes in Esan are verb-based by providing data in Esan indicating the class a prefix brings when attached to a word. Examples:

$\begin{array}{cll}\text { (4) Prefix } & \text { Base form (V) } & \text { Derived noun (N) } \\ e- & k p a \text { 'vomit' } & \text { ekpa 'vomit' } \\ i- & l o \quad \text { 'think' } & \text { ilo 'thought' } \\ o- & d a n \text { 'wrestle' } & \text { odan 'wrestle' }\end{array}$

Ejele's study summarises that in the Esan language, positional affixes include prefix, suffix and circumfix. Suffixes are attached to the end of words to change the meaning or class of the word. Circumfix is a process whereby part of a morpheme is attached to the beginning of a root and the rest is added to the end of the word simultaneously. Circumfix surrounds the word and it is used to form new words in the language. The work of Ejele is similar to this work as both look at affixation as a word formation process but differ in language. Ejele's study focuses on Esan language while this study examines headedness in affixation processes in Urhobo.

Igala affixes include prefix, interfix and suprafix. By interfixation, it involves the placement of an affix between two identical stems either to create a new word or alter the meaning of the existing word (Omachonu, 2001). Examples:

$$
\begin{array}{cllll}
\text { (5) } \text { unyi } & \text { 'house' } & \text { unyi tu unyi } & \text { 'any house' } \\
\text { ene } & \text { 'person' } & \text { ene tu ene } & \text { 'any one' } \\
\text { ogba } & \text { 'line' } & \text { ogbatuogba } & \text { 'any line' }
\end{array}
$$

$t u$ is an interfix attached to two roots in Igala to derive new words. This is also possible in the Yoruba language. Examples:

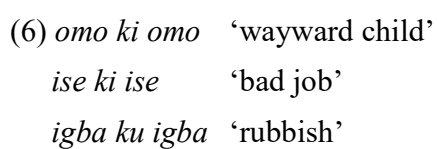

In suprafixation, affix is not represented by a segment but by what is called a prosodic feature such as tone, stress or intonation (Oyebade, 1992). Urhobo does not observe suprafix as a process of affixation which makes Oyebade's idea differ from this work.

Agbedo (2000) explains that prefixation in Igbo is verb-based. He further explains that Igbo prefixes are infinitive and participle markers attached to verb roots. Abonyi, Nwaozuzu \& Agbedo (2013) note that prefix, interfix and suffix are obtainable in Igbo. They explain that nouns do not lend themselves to affixes in Igbo. 
Kamai (2012) studies corpus-based description of morphological processes in Jukunkona language of Nigeria. The study examines the entire range of morphological processes in Jukunkona in line with the paradigm outlined by Mathews. The study reveals three types of morphological processes in Jukunkona, which are affixation, reduplication and modification. Kamai notes that in Jukunkona, grammatical relationships are expressed by the addition of prefixes to a base or root word.

Furthermore, the paper discusses modification as a morphological process that involves the alteration of a linguistic form through borrowing, phonetic assimilation or morpho-phonemic variation. The study concludes that Jukunkona shares morphological universals identified in languages of other phyla. The fact that Kamai's study relied only on the intuition of the native speakers rather than a combination of intuition and as such, corpus modification could not be determined. Kamai's study differs from this work in terms of the language studied and the theories used.

Ojonugwa (2015) studies affixation in Igala. The focus of the paper is to explore affixation as a process of word formation in Igala, to identify the kind of affixes attestable in Igala and to examine the meaning derived when these affixes are attached to the root or stem using a descriptive approach. The paper discovers that affixation is a productive process of word formation in Igala and precisely prefixation and suprafixation are found to be more productive. There is also evidence of interfixation in the language. The study also confirms that prefixation is more productive in the language and these affixes which are added at the beginning are mostly derivational morphemes and few cases of inflectional morphemes. The study also confirms that when the affixes (especially the prefixes) are attached at the beginning of a word in Igala, two things happen: a change in the word class and a change in the grammatical function of the word. Examples are:

\begin{tabular}{lllll} 
& Prefix & \multicolumn{2}{l}{ Stem (V) } & Derived (N) \\
a. & $a-$ & $k p a$ & 'kill' & akpa 'killer' \\
b. & $e-$ & $m o$ & 'drink' & emo 'drinking' \\
c. & $i-$ & $l a$ & 'buy' & ila 'act of buying' \\
d. & $u-$ & $k o$ & 'instruct' & uko 'instruction'
\end{tabular}

(Ojonugwa, 2015: 67)

The study helps to confirm that Igala language is a synthetic language because it forms words by affixing a given number of dependent morphemes to the root morpheme. The paper recommends the needfulness in the writing of Igala grammar and the broad impact the work would have on linguists who may wish to explore this phenomenon in other languages. Both studies examine word formation process but in different languages. Ojonugwa's study used a descriptive approach while this study adopts a feature percolation theory for analysis of data. 


\section{A Feature Percolation Convention of Affixation Processes in Urhobo}

Onwukwe (2018) investigates percolation principle perspective of verb-suffix distinction in Igbo compounds. The article adopts a descriptive survey with percolation convention as a theoretical framework. The findings reveal that when a verb compound in Igbo obeys percolation principle, it means that the second elements of such a compound is a verb otherwise, it is a suffix. The paper also finds out that Igbo verb compounds are left-headed. The study concludes that percolation convention provides a clearer distinction of verbsuffix in Igbo verb compounds. The paper recommends other studies in this direction in form of testing the percolation principle in Igbo. Onwukwe (2018) is similar to the work understudy because it adopts feature percolation theory in accounting for headedness in morphological processes in Urhobo. While Onwukwe studied percolation principle in Verb-compounds in Igbo, this work examines affixation processes in Urhobo.

Waya and Babarinde (2018) study the suffixation processes in the morphology of Tiv verbs. The study examines the internal structure of Tiv verbs as well as the suffixation paradigm and the possible phenomenon of tone as an item-and-arrangement (IA) and item-and-process (IP) models as theoretical frameworks for the analysis of the data. The study reveals both regular and irregular patterns in Tiv verb realisations. The study also reveals that the substitution of certain segments or modification of tone accounts for past tense. The paper observes that to realise aspects, the suffixes - $n$, -on, -en-, -un or tone are reflected on verb roots. The paper also observes that some verbs do not take an overt suffix but a vowel extension to indicate a dynamic imperative formation. The study recommends further research on how tone and affixes interact in the expression of grammatical categories. Waya \& Babarinde's study is similar to this present research work because they involve the use of theory for analysis.

Ibeneme (2021) investigates the affixation processes in the Ibibio language. The specific objectives of the study are to: identify the types of affixation in the Ibibio language, show the manifestation of the various types of affixation evident in the Ibibio language, identify the various changes that occur during the process of affixation and determine if the process of affixation in the Ibibio language is inflectional, derivational or both. The study adopts the emergent research design. The study identifies five types of affixes in the Ibibio language viz: prefix, suffix, interfix, infix and suprafix. The findings further reveal that the verb in the Ibibio language serves as the root in deriving new words and also inflects to show its relationship with already existing words in a construction. The prefix is seen as being very productive in the Ibibio language because it plays both inflectional and derivational roles. The study discovers that suffixes are used to form reversives, reciprocal actions and word opposites. Interfixes are also seen as a rare type of affixation as it is used to form only numerals, while infixing a vowel inside the root can cause a meaning change in the root. The study confirms that circumfix is not evident in the Ibibio language and 
what are seen as circumfixes are negative constructions. The study further discovers tone as performing lexical function, which contrast meaning in Ibibio. This study is similar to this work because they both examine affixes but in different languages. The theoretical frameworks are not the same. Ibeneme used construction morphology while this work adopts the feature percolation theory to account for heads in Urhobo.

\subsection{Summary of literature review}

To the best of the researcher's knowledge, no work in Urhobo adopts the feature percolation theory as a framework for analysing affixes. This study examines headedness in affixation processes in Urhobo, using the feature percolation theory as a framework for the analysis of data.

\subsection{Theoretical framework}

The theoretical framework employed in this study is feature percolation theory (FPT). FPT is a set of four mechanisms originally proposed in Lieber (1980) that copy the properties of words to the node that immediately dominates them. In feature percolation theory, features are distributed across appropriate terminal nodes in the non-surface syntactic tree, resulting in concord. It discusses the needs of the realisational morphological component, which will act on the representations generated via percolation in order to calculate correct morphological forms. Lieber (1980) assumes that morphemes are inserted into unlabeled trees, and these trees are then labeled by means of the following FPT:

FPC I: All features of a stem morpheme, including category features, percolate to the first non-branching node dominating that morpheme;

FPC II: All features of an affix morpheme, including category, features, percolate to the first branching node dominating that morpheme;

FPC III: If a branching node fails to obtain features by FPC II, features from the next lowest labeled node automatically, percolate up to the unlabeled branching node;

FPC IV: If two stems are sisters (i.e. they form a compound), features from the right-hand stem percolate up to the branching node dominating the stems.

FPT shows that the formal properties of percolation needed to account for the blocking of one feature by another, and for feature ordering, can be unified. A simple, iterative algorithm is adduced for percolation. The basic claim of the theory is that the agreement of the morphological, syntactic and semantic features of a word must be the same as the features of its roots. The features of the root admit the subsidiary features and characterize them. In feature theory, the concept of head is essential. Mbah (1999) notes the universality of the concept of head. Here, whatever defines the grammatical category of the word or provides additional semantic information refers to the head of the word. For instance, if an affix or a reduplicant defines the grammatical class of the word, the affix or the reduplicant is the head of the word. This is also applicable to reduplication and compounding. Selkirk 


\section{A Feature Percolation Convention of Affixation Processes in Urhobo}

(1982) and Di Sciullo \& Williams (1987) also make use of the notion 'head'. However, since the feature percolation theory allows an element to be the head of a word, the researcher finds it a more comprehensive and adequate framework for this study.

The term 'head' in linguistics is the syllable used to determine the grammatical or lexical class of a word. Head is a constituent of an endocentric construction that if standing alone, could perform the lexical or grammatical function of the construction. Babarinde (2009) notes that the concept of head is originally syntactic but linguists such as Williams (1981) and Lieber (1983), have encroached it into the circle of morphology. Heads are essential in establishing the direction of branching. The head of a word is the element that determines the class of the word. Affixation as mentioned above involves the attaching of a syllable to a root to change the grammatical class or the meaning of the word. Sometimes, it maintains the grammatical class or meaning of the word. Crystal (1985) observes that affixation involves the addition of grammatical or lexical functions to the root. An affix is a morpheme that is attached to a word stem to form a new word or word form. In orthography, the terms for affixes may be used for the smaller elements of conjunct characters. Affixation operates in different ways in different languages like Urhobo and they are used to determine the head of a word.

\section{Prefixation in Urhobo}

Prefixes are attached to the beginning of a root to change its meaning or grammatical class. The word pre means 'before' while fix means 'attach' or 'add'. In Urhobo, a prefix can determine the head of a word or phrase. Prefixes are attached to the beginning or the initial position of a word or root either to change the class or to create new words in Urhobo. According to Abonyi et al. (2013), prefixation is a process by which an affix or a morpheme is attached at the word initials or at the beginning of the word. Prefixes cannot be attached to any other position of a word. A prefix is usually a letter(s) which is meaningful when attached to the word. Instances include the following:

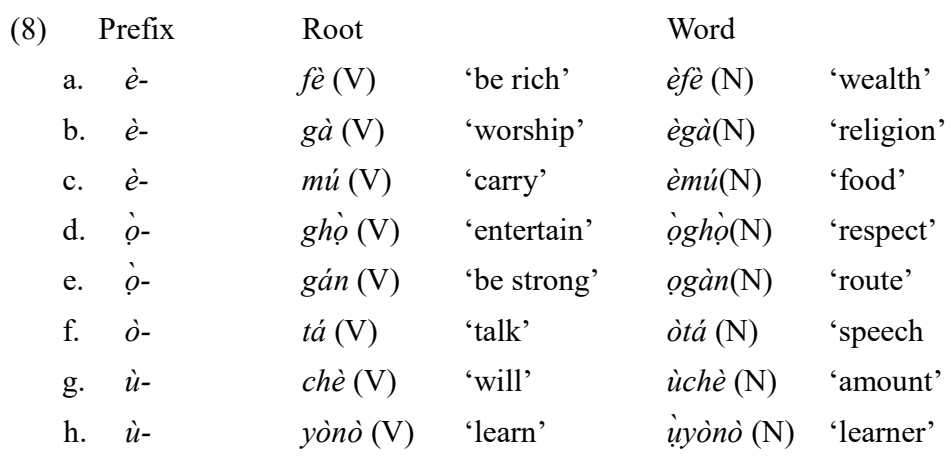


Example (8) above explains the changes that occur when the V syllabic structure is attached to the root. The prefixes attached change the grammatical class of the words from verb to noun. This shows that prefixation in Urhobo changes the lexical class of the root words.

The word èfè in (8a) is made up of a prefix $\grave{e}$ - and a root fè which means 'be rich'. It could be observed that $f \grave{e}$ on its own is a root (i.e. verbal morpheme), but the prefix $\grave{e}$ attached to it changed the grammatical class to a noun. As enunciated in feature percolation theory, the constituent that determines the lexical class of a word is the head.

In (8b), gà in isolation means 'worship' (V) but when prefixed by $\grave{e}$-, its lexical class changes from verb to noun. As enunciated by proponents of feature percolation, when the affix changes the lexical class of the root word, the affix is the head of the word (Williams, 1981).

The word òtá in (8f) means 'speech', consisting of two morphemes: free and bound

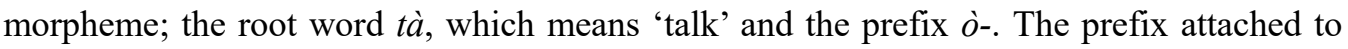
the root changed the class of the word from verb to noun. As stated in feature percolation theory, to account for the head of a word, the constituent that changes the lexical class of the word forms the head. In line with this assertion, the prefix $o$ - therefore, is the head of the word.

\section{Suffixation in Urhobo}

Suffixes are attached to the end of a word, which results to change in the new word derived. Suffixes in Urhobo are commonly past tense markers with a $r \mathrm{~V}$ syllabic structure, where the $r$ is constant but the vowel varies. Instances include the following:

(9)

\begin{tabular}{lll}
\multicolumn{3}{c}{$\operatorname{Root}(\mathrm{V})$} \\
a. & sé & 'call' \\
b. & $s i$ & 'write' \\
c. & $d e ́$ & 'buy' \\
d. & tá & 'talk' \\
e. & $m r e ́$ & 'see' \\
f. & $h w e ́$ & 'kill' \\
g. & $g b e ́$ & 'dance' \\
h. & $r a ́$ & 'go' \\
i. & $r u ́$ & 'do' \\
j. & $g b a ́$ & 'tie'
\end{tabular}

Suffix
$-r e ́$
$-r i ́$
$-r e ́$
$-r o ̣$
$-r e ́$
$-r e ́$
$-r e ́$
$-r e ́$
$-r u ́$
$-r o ́$

Word

$\begin{array}{ll}\text { sérè } & \text { 'called' } \\ \text { sirì } & \text { 'wrote' } \\ \text { dérè } & \text { 'bought' } \\ \text { tárọ } & \text { 'talked' } \\ \text { mrẹrẹ } & \text { 'saw' } \\ \text { hwérè } & \text { 'killed' } \\ \text { gbérè } & \text { 'danced' } \\ \text { ráre } & \text { 'went' } \\ \text { rúrù } & \text { 'did' } \\ \text { gbárọ } & \text { 'tied' }\end{array}$

In the data above, the $r \mathrm{~V}$ marker (past tense marker) attached to the verbs changed the tense from present to past tense. The suffixes attached to the root words do not result any change in the grammatical class but changes occurred in the tense as well as additional 


\section{A Feature Percolation Convention of Affixation Processes in Urhobo}

semantic information was provided as seen in the examples above. In essence, past tense notion is actualized through suffixation in Urhobo. Another phenomenon to note in the above examples is that the vowel in the $r \mathrm{~V}$ suffix must belong to the vowel group of the vowel in the root. In other words, the rule of vowel harmony is observed during this suffixation process.

\section{Circumfixation in Urhobo}

Circumfixation is a type of affix which is divided into two parts: one of the parts acts as a prefix (attached to the beginning of the root) and the other acts as a suffix (attached to the end of the root) to either change the class or the meaning of the word. It is made up of two separable syllables, which surround a stem or root. Scholars such as Scalise (1984) argued that all cases of alleged circumfixation could be reduced to suffixes and a concomitant prefix. The common circumfixation in Urhobo includes gerundive/infinitive morpheme (Aziza, 2011). Examples include:

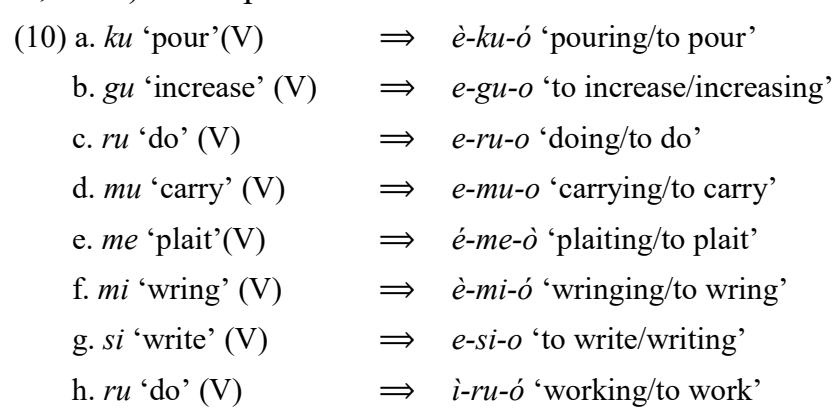

Examples above are gerundives/infinitives in the Urhobo language. Gerunds or infinitives in Urhobo are formed when attaching a syllable before and after the root through a process known as circumfixation as seen in the examples above. In example 10 (a-g), the prefix $e$ - and suffix - $o$ were attached to the root verbs whereas in 10(h), the prefix $i$ - and the suffix - $o$ are bounded to the root verb $r u$. Due to the fact that both the prefix and suffix combine to form the circumfix, there was a lexical class change from verb to noun. As such, the prefix and suffix are what formed the head of the word, which indicates the double headedness of the circumfix markers.

\section{Conclusion}

Affixation is the most common strategy that human languages employ for the derivation of new words and word forms. It is a rich source of word formation in the Urhobo language. It also depends on the placement (positioning) of words. The study addresses headedness in affixation, in Urhobo, using the feature percolation theory as a theoretical framework. The findings reveal the possibility of an element percolated to be the head of a word following 
the principle of Lieber (1980). The study discovers that an element percolates to be the head of the word since it determines the grammatical class of the word or rather gives additional semantic information to the word. For instance, the attachment of a prefix or suffix to a root either changes the grammatical class of the word or even extends the meaning of the word. The study observes prefix to be left-hand head rule while suffix is right-hand head rule. The study discovers that the attachment of a suffix to a root does not change the grammatical class of the word but rather, gives additional semantic information to the word and percolates to be the head of the word. The head of a circumfix moves from left and right to the maximal level and percolates to the head of the word i.e. the joining of the prefix and suffix to be the head of the word. The study discovers double headedness of the circumfix markers.

\section{References}

Abonyi, D. O., G. I. Nwaozuzu \& C. U. Agbedo. 2013. A Comparative Study of the Morphology of the Igbo and Igala Languages [A]. Nsukka Working Papers in Languages and Linguistics and Literature [C], 1:84-96.

Agbedo, C. U. 2000. General Linguistics: An introductory reader [M]. Nsukka: Ace Resources Konzult.

Agbedo, C. U. 2015. General Linguistics: Historical and contemporary perspectives [M]. Nsukka: KUMCEE- Ntaeshe Press Inc.

Amajoyi, G. N. 2017. Feature Percolation Theory [A]. In B. M. Mbah (ed.) Theories of Contextual Linguistics, Articles in Honour of Professor Gabriella Ihuaruugo Nwaozuzu [C]. Nigeria: Amaka Dreams Ltd, 25-40.

Aziza, R. 2011. Urhobo Morphology [A]. In O. Yusuf (ed.). Basic Linguistics for Nigerian Languages [C]. Ijebu-Ode: Shebiotimo Publications, 295-308.

Babarinde, S. O. 2009. Morphology: Its basics and application [M]. Nsukka: Paschal Communications.

Crystal, D. 1985. A Dictionary of Linguistics and Phonetics [M]. New York: Basil Blackwell.

Di Sciullo, A. M. \& E. Williams. 1987. On the Definition of Word [M]. Cambridge: The MIT Press.

Ejele, P. E. 2005. Wordformation Processes in Esan [A]. In O. Ndimele (Ed.) Globalisation and the Study of Languages in African [C]. Port Harcourt: Grand Orbit Communications Ltd, 35-66.

Elugbe, B. O. 1989. Comparative Edoid: Phonology and lexicon [M]. Port Harcourt: University of Port Harcourt Press.

Haris, Z. S. 1951. Methods in Structural Linguistics [M]. Chicago: University of Chicago Press.

Ibeneme, J. C. 2021. Affixation in the Ibibio Language: A construction morphological analysis [D]. MA Thesis. Nsukka: University of Nigeria.

Kamai, R. 2012. Corpus-based Description on Morphological Processes in the Jukunkona Language of Nigeria [J]. Nsukka Journal of African Languages and Linguistics, 7(2):27-35.

Lieber, R. 1980. On the Organisation of the Lexicon [D]. PhD Dissertation. Durham: University of New Hampshire.

Lieber, R. 1983. Argument Linking and Compounds in English [J]. Linguistic Inquiry, 14:251-285.

Mbah, B. M. 1999. Studies in Syntax: Igbo phrase structure [M]. Nsukka: Prize publishers.

Ndimele, O. M. 1999. A First Course on Morphology and Syntax [M]. Port Harcourt: Emhai Printing \& Publishing Co.

Ojonugwa, N. J. 2015. Affixation in Igala [A]. In R. I. Okorji, C. A. Eme \& G. S. Omachonu (eds.). Contemporary Issues in Linguistics and Language Studies: A festschrift in honour of Prof. Clara Ikekeonwu [C]. Enugu: Rossen Publications Ltd, 24-32.

Omachonu, G. S. 2001. Igala Morphological Process [J]. Nsukka Journal of Linguistics and African 


\section{A Feature Percolation Convention of Affixation Processes in Urhobo}

Languages, 2(3):55-65.

Owolabi, K. 1995. Language in Nigeria: Essays in honour of Ayo Bamgbose [M]. Ibadan: Group Publishers.

Onwukwe, C. 2018. Percolation Principle of Verb-Suffix Distinction in Igbo Verb Compounds [J]. Africology: The journal of Pan African studies, 11(2):72-82.

Oyebade, F. O. 1992. Morphology [A]. In O. Yusuf (ed.). Introduction to Linguistics [C]. Ilorin: Unilorin Press, 307-321.

Scalise, S. 1984. Generative Morphology [M]. Dorchrecht: Foris Publications.

Selkirk, E. O. 1982. The Syntax of Words [M]. Cambridge: The MIT Press.

Waya, D. \& S. O. Babarinde. 2018. The Suffixation Processes in the Morphology of Tiv Verbs [J]. Language Matters, 49(1):131-148.

Williams, E. 1981. On the Notions Lexically Related and Head of Word [J]. Linguistic Inquiry, $12: 245-274$

Zwicky, A. M. 1985. How to Describe Inflection [J]. Berkley Linguistics Society, 11:372-386. 